\title{
Peat Stabilization using Gypsum and Fly Ash
}

\author{
Kolay, P.K. and Pui, M.P.
}

\begin{abstract}
This paper presents the stabilization of local peat soil from Matang, Sarawak, using gypsum and fly ash. Peat soil has been identified as one of the major groups of soils found in Malaysia, which has high compressibility and low shear strength. Presence of soft or peaty soil is a major problem encountered by civil engineers in Sarawak. Different percentages of gypsum (i.e., 2, 4, 6 and 8\%) and fly ash (i.e., 5, $10,15,20$ and 25\%) were added into peat soil at optimum moisture content and it's maximum dry density determined by standard Proctor test. Unconfined compressive strength (UCS) test were conducted to determine the strength gain after 7, 14 and 28 days of curing periods. Physical properties of the peat soil have also been studied for identification and classification purposes. The unconfined compressive strength test results show that the peat soil gained strength due to the addition of different percentages of admixtures such as gypsum and fly ash and the strength also increases with the increase of curing periods.
\end{abstract}

Keywords: Peat Soil, Stabilization, Gypsum, Fly Ash, Unconfined Compressive Strength (UCS)

\section{INTRODUCTION}

P eat soil is soft, wet and contains very high percentages of organic matter from plant materials. Peat covers a major area in

Malaysia especially in the land of Sarawak. Peat soil usually is black to dark brown in color. The presence of organic matter in peat leads to high potential for further decomposition as a result of changing environment conditions. Peat also exhibit high natural moisture content (up to 800\%) [1]. As demand for lands goes up with the increase of population causes engineers to think about the future development of peat land. Due to the very low shear strength and high compressibility of peat soil, engineers need alternative ways to develop a peat land for construction. Different approaches are used for the improvement of peat soil. Soil stabilization such as compaction and soil mixing with the addition of chemicals is to modify the soil condition so that construction can be done easily without any risk [2]. Most common way for soft or peat soil treatment is by excavating the soft or peat soil and replacing it with good granular or sandy soil but this way of soil treatment is not encouraged because of the uneconomical design. If heavy loaded buildings are to be constructed on a soft peat soil layers, piled foundations can be used to transfer the loading to the rock. But if lightly loaded buildings or a road are to be constructed, it is not economical to construct the structures on a piled foundation. The method of pre-consolidation by preloading is the most widely used method by the engineers to improve the soil. But the one of the disadvantage of preloading method is it requires a long period of time. Soil stabilization is very important to strengthen the peat soil. Therefore, it is more economical to improve the strength and stiffness of the soil so that the structures can be built on top of soft soil. Soil stabilization by using chemical admixtures involves the treatment of the structures and fabric of the soil. The chemical reaction that occurs within the soil will results in changes in moisture content, shear strength, compressibility, $\mathrm{pH}$ values and other physical, chemical and engineering properties of the soil. The chemical stabilizer will accelerate the bonding in the soil but the bonding and the rate of the boding depends on the type of stabilizer used. Several researchers have done researches on the use of fly ash and gypsum on soft soil stabilization [3-13]. However, the study of possible improvement of soft or peat soil stabilization by using different types of admixtures seems to be limited in Sarawak, Malaysia. The objective of this paper is to demonstrate the feasibility of stabilizing peat soil with fly ash and gypsum as admixtures and to evaluate the response of peat for soil improvement for construction on it.

\section{PHYSICAL PROPERTIES OF PEAT}

Peat is a product of decomposition of organic matter from plants and animals. It has a great capacity for taking up and holding water. High water content results in high pore volume leading to low bulk density and low bearing capacity [14, 15]. Void ratio is an indicator for the compressibility of the material. Void ratios of peats and organic soils are generally higher 
than for inorganic soils. For submerged peats and organic soils void ratio linearly varies with water content. The higher specific gravity indicates a higher degree of decomposition and low mineral content. An approximate and easier method of determining specific gravity is to use ash content or organic content. The ash content is an indication of the organic content in the peat. The unit weight is influenced by the water content and organic content of the peat. Unit weights will increase with the increment of specific gravity. Unit weight of peat is typically lower compared to inorganic soils. Peat will shrink extensively when dried.

\section{ENGINEERING PROPERTIES OF PEAT}

The shear strength of peat soil is very low; however, the strength could increase significantly upon consolidation [16]. Shear strength is associated with several variables such as the origin of soil, water content, organic content, and degree of decomposition. The shear strength of peat is determined based on drained condition. Considering the presence of peat soil is almost always below the groundwater level, the determination of undrained shear strength is also important. The compression behavior of fibrous peat is different from clay soil. Initial compression occurs instantaneously after the load being applied; the primary and secondary compressions are time dependent. Primary consolidation is due to dissipation of excess pore water pressure caused by an increase in effective stress whereas secondary compression takes place under constant effective stress after the completion of dissipation of excess pore water pressure [14]. Compression of fibrous peat continues at a gradually decreasing rate under constant effective stress, and this is termed as the secondary compression. The secondary compression of peat is thought to be due to further decomposition of fiber which is conveniently assumed to occur at a slower rate after the end of primary consolidation [17]. Permeability is one of the important properties of peat because it controls the rate of consolidation and increase in the shear strength of the soil [18]. Previous studies indicated that the peat is averagely porous, and certifies the fact that fibrous peat has a medium degree of permeability [19].

\section{METHODOLOGY}

Physical properties such as moisture content, specific gravity, particle size and liquid limit are determined to establish the basic characteristics of the peat soil. The peat soil was classified based on von Post scale for degree of decomposition, fiber content, loss on ignition and organic content. Engineering property such as standard Proctor test and unconfined compressive strength also has been studied.

After the soil sample collected from Matang, Sarawak, approximately at the depth of 0.5 to $1.0 \mathrm{~m}$, at first sun-dried followed by grinding and sieving. The soil particles that passed through $1.18 \mathrm{~mm}$ sieve are collected to conduct different test with different percentage of admixtures. The procedure for conducting the experimental investigation is based on the British Standard BS 1377:1990 and ASTM standard. Tests on different proportion of fly ash and gypsum are designed to obtain the most suitable proportion of stabilizer that will improve the peat soil sample most in term of strength and other physical and engineering properties. Tests on original peat soil alone also been conducted in order to access the improvement made on the peat soil samples.

After obtaining the value of maximum dry density and optimum moisture content of the sample from standard Proctor test, the specimens were tested using stabilized agents such as gypsum of 2, 4, 6, and 8\%; and fly ash of 5, 10, 15, 20, and $25 \%$ of dry weight of the sample. To prepare a cylindrical sample for UCS test, a poly vinyl chloride (PVC) pipe with 50 $\mathrm{mm}$ diameter and $100 \mathrm{~mm}$ height has been used. As shown in Figure 1, a PVC pipe cut into half so that the soil sample can be easily extracted without disturbing the structure of the soil was used as a mould. Two cap (top and bottom) is used to seal the soil sample once the sample is filled into the PVC pipe. After sample preparation, the sample has been kept for approximately 24 hours before it being immersed in the water tank for curing. The unconfined compressive strength tests were conducted after curing period for 7, 14 and 28 days to investigate the strength of treated soil.

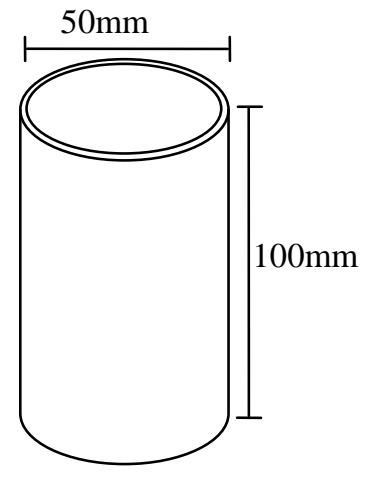

(a)

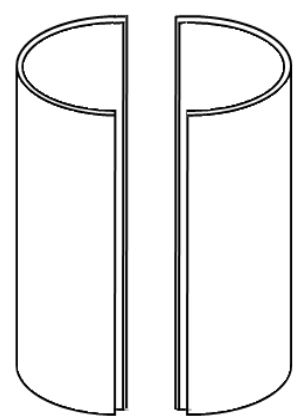

(b)

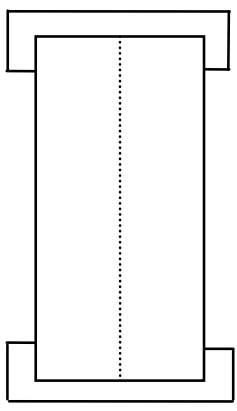

(c)

Figure 1: Mould for UCS soil samples preparation 


\section{SOIL PROPERTIES' TEST RESULTS}

The physical and geotechnical properties of the soil samples were shown in Table 1. The preliminary identification of the soil was made based on the index properties testes conducted on the peat soil sample. The peat can be considered as very soft and dark brown peat which contained a large amount of fiber by using visual identification. There were lots of plant structures such as roots in the soil. The texture is quite coarse and may results in large permeability.

The peat was classified based on the degree of humification known as von Post scale and the organic and the fiber content in the soil sample. The degree of humification test was done by based on the appearance of soil water that is extruded when a sample of soil is squeezed in the hand.

Loss on ignition test has been conducted on the samples collected to obtain the organic content of the samples. From the Table 1 it can be observed that the sample has very high value of loss of ignition and organic content. The value of liquid limit is high because the sample contains lots of fiber which results in high water absorption capacity. Standard Proctor test was carried out for soil sample in order to find out the compaction characteristics such as the optimum moisture content (OMC) and maximum dry density (MDD) for the sample.

Table 1. Physical and geotechnical properties of peat soil

\begin{tabular}{|c|c|}
\hline Parameters & Results \\
\hline Natural moisture content, MC (\%) & 678.47 \\
\hline Von Post humification for peat & $\mathrm{H} 4$ \\
\hline Fiber content $(\%)$ & 70.83 \\
\hline Specific gravity, $\mathrm{G}_{\mathrm{s}}$ & 1.21 \\
\hline Loss on Ignition, LOI $(\%)$ & 95.21 \\
\hline Organic content, OC $(\%)$ & 94.47 \\
\hline Liquid Limit, LL & 150 \\
\hline Maximum Dry Density, MDD, $\gamma_{\mathrm{d}}(\mathrm{gm} / \mathrm{cc})$ & 0.56 \\
\hline Optimum Moisture Content, OMC $(\%)$ & 95.17 \\
\hline
\end{tabular}

\section{UNCONFINED COMPRESSIVE STRENGTH}

Unconfined compressive strength (UCS) test was performed on the cured peat soil sample with different percentages of stabilizers and the results are presented in Figure 2 and 3. UCS test is the most common test to determine the strength of stabilized soil. For each UCS test, the stress - strain relationships was determined. The sample was mixed with various percentages of gypsum (i.e. 2, 4, 6 and 8\%) and fly ash (5, 10, 15, 20 and 25\%). Figure 2 shows the gain in UCS with respect to various percentages of gypsum added and to different curing periods, where as Figure 3 shows the similar test results with respect to various percentages of fly ash added to peat soil with different curing periods.

In general, the compressive strength value indicates that all admixture treatment types resulted in strength gain. It can be noticed that the strength of treated soil increased with curing time. Most of the strength gain occurred within the first seven days of curing. The results show that higher strength was achieved for the sample mixed with fly ash. This fast gain of strength is believed to be related to the initial rapid hydration that takes place with these admixtures. The UCS strength value for peat treated with fly ash has the highest level of strength gain and these seem to be a slower rate of strength gain after 14 days of curing. This trend is the same with the sample mixed with gypsum where the UCS values for gypsum seem to stabilize after 14 days of curing, the strength only increase slightly compared with 14 days of curing and 28 days of curing. The UCS value increases constantly for the sample mixed with gypsum and fly ash. But for the sample mixed with $25 \%$ of fly ash, the samples have higher gain of strength when compared to samples mixed with other percentages of fly ash.

The results show that soil treatments were effective in increasing the strength of the samples. The UCS values increase with addition of gypsum and fly ash to its maximum at $6 \%$ of gypsum and $20 \%$ of fly ash after that it dropped at $8 \%$ of gypsum and $25 \%$ of fly ash. This decrease in the UCS value after the addition of $8 \%$ gypsum may be due to the excess gypsum added to the soil and therefore formed weak bonds between the soil particle and the cementitious compound formed. The reason for the fly ash added soil' strength drop is not certain, but it could be related to sample degradation during the curing. But after 28 days of curing, the sample treated with $25 \%$ of fly ash gain more strength when compared with the sample treated with $20 \%$ of fly ash. Strength improvement levels were observed to be highest for fly ash treated soil where most improvement was achieved with $20 \%$.

In general, the UCS increases with the increase of percentages of gypsum added to the soil sample, but the UCS values starts to decrease after $6 \%$. The strength increases with the period of curing for all percentages of gypsum added. The 
maximum strength obtained is from the sample with 6\% gypsum added with 28days of curing which is $44.94 \mathrm{kPa}$. For Fly Ash, the UCS values increase with the increases of percentage of fly ash added to the soil sample except for $25 \%$ fly ash with curing time of 7 days and 14 days. The sample with $25 \%$ fly ash added to the soil sample has slightly higher value than $20 \%$ fly ash added. The maximum strength obtain is from the sample with $25 \%$ fly ash added with 28 days of curing which is $109.69 \mathrm{kPa}$. For minor percentages of stabilizer added to the sample, gypsum shows high gain of strength even though the highest strength is only $44.94 \mathrm{kPa}$. The strength gains in samples with fly ash are the highest when highest percentages of stabilizer are added. In comparison by curing time, the samples increase in strength with the increase in curing time. In general, the soil samples gain more strength with addition of fly ash as compared to gypsum.

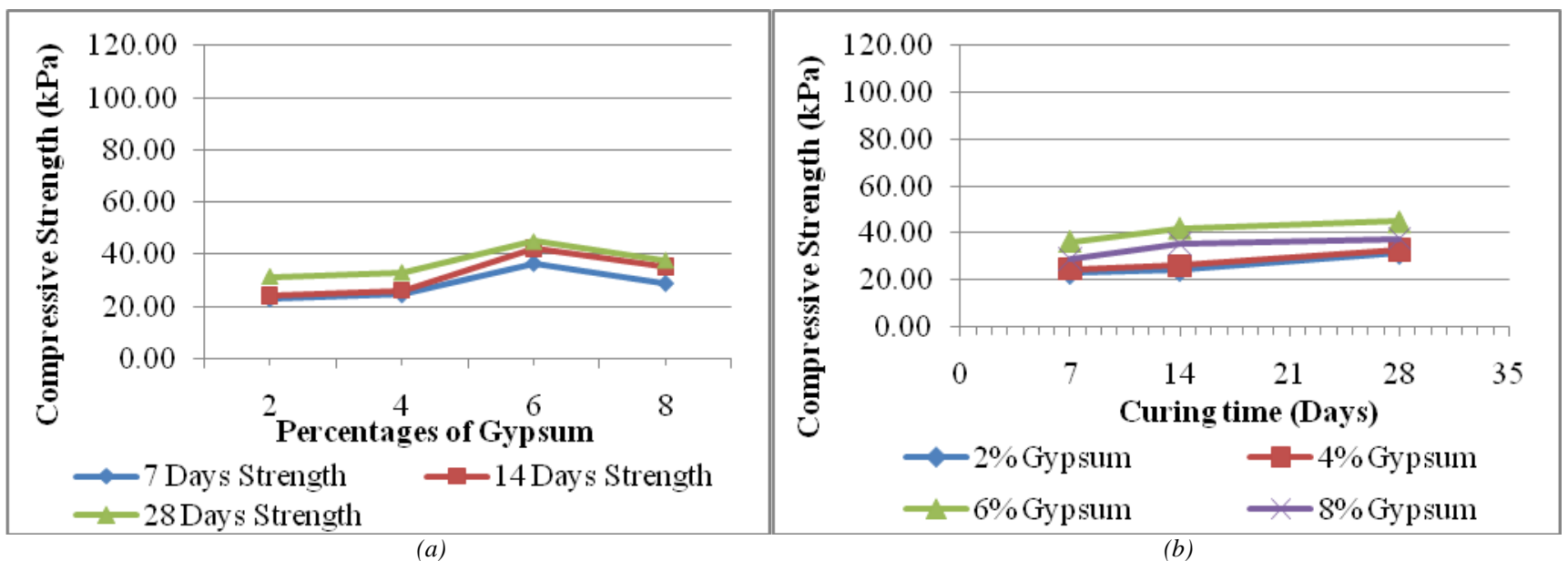

Figure 2. UCS test results for sample with respect to various (a) percentages of gypsum added (b) curing periods

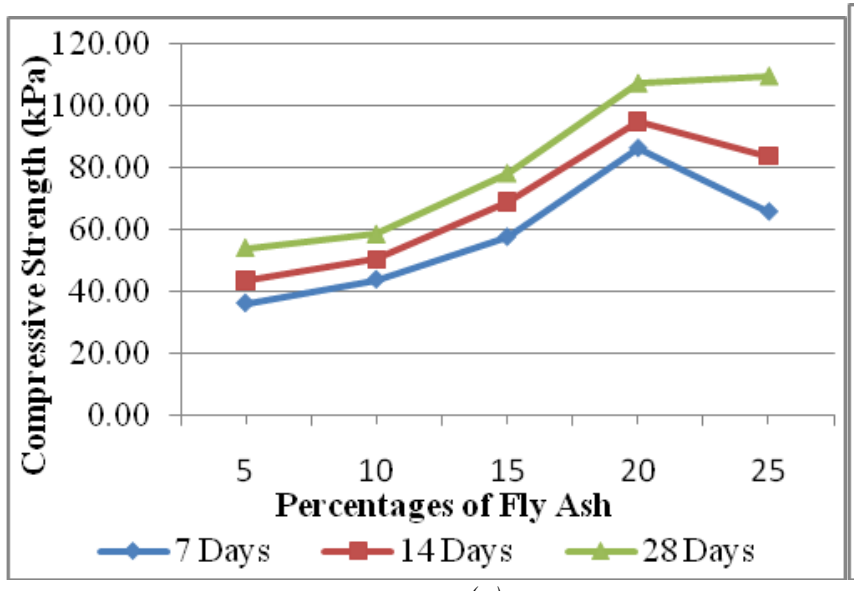

(a)

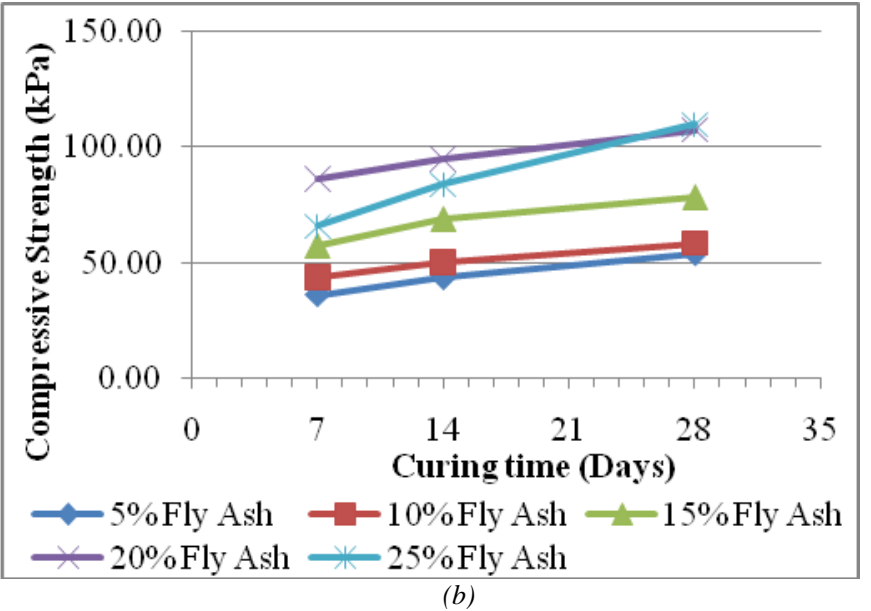

(b)

Figure 3. UCS test results for sample with respect of various (a) percentages of fly ash added (b) curing periods

\section{CONCLUSIONS}

In the present study, a laboratory investigation involving use of gypsum and fly ash for the improvement of strength of peat soil was carried out. In general, the test results indicate that peat soil treated with gypsum and fly ash result in improvement of strength of the soil as measured from unconfined compressive tests. In general the compressive strength gain was observed primarily in the first 14 days of curing and then had a tendency to slow down the rate of strength gain afterwards. For $8 \%$ gypsum treated soil, drop in strength was observed when compared to $6 \%$ gypsum treated soil. Similar trend has been observed with $25 \%$ fly ash treated soil (compared to $20 \%$ fly ash) except for 28 days of curing, where slightly drop in strength was observed.

From the series of laboratory investigation carried out, the following conclusions can be made:

- The soil sample collected from Matang is categorized as peat soil.

- The unconfined compressive strength (UCS) values increase as the percentages of gypsum and fly ash added increase except for $8 \%$ of gypsum and $25 \%$ of fly ash.

- The unconfined compressive strength (UCS) values increase as the curing period increase for all percentages of stabilizer added.

- The average value of unconfined compressive strength (UCS) from test results are 31.37, 32.92, 44.94 and $37.70 \mathrm{kPa}$ for 2, 4, 6 and $8 \%$ gypsum added respectively for 28 days curing. 
- The average value of unconfined compressive strength (UCS) from test results are 54.01, 58.47, 78.17, 107.35 and $109.69 \mathrm{kPa}$ for $5,10,15,20$ and $25 \%$ fly ash added, respectively for 28 days curing.

This improvement favorably indicates the use of cheaply available local fly ash in stabilization of peat in sub-grade, embankment etc.

\section{ACKNOWLEDGMENTS}

The authors would like to express deep gratitude for the technical supports offered by the Geotechnical laboratory staff and the Construction on Soft Soil Group members, Universiti Malaysia Sarawak (UNIMAS), Sarawak, Malaysia.

\section{REFERENCES}

[1] Deboucha, S., Hashim, R. \& Alwi, A. Engineering Properties of Stabilized Tropical Peat Soils. EJGE, Vol. 13, Bund. E, 2008, pp. 1-9.

[2] Kawamura, M. Fundamental Studies on the Fabric of Soil Cement Mixture and Its Mechanical Properties, Kyoto University, 1970, Japan.

[3] Hughes, P., Glendinning, S. "Deep dry mix ground improvement of a soft peaty clay using blast furnace slag and red gypsum". Quarterly Journal of Engineering Geology and Hydrogeology. Vol. 37, No. 3, 2004, pp. 205-216.

[4] Degirmenci. N, Okucu. A, and Turabi. A. "Application of phosphogypsum in soil stabilization”. Building and Environment, Vol. 42, No. 9, 2007, pp. 3393-3398

[5] Ameta, N. K., Purohit, D.G.M., Wayal, A.S. and Sandeep D. "Economics of Stabilizing Bentonite Soil with Lime-Gypsum". Electronic Journal of Geotechnical Engineering, 2007, Vol. 12, Bundle E.

[6] Anil, M. (2006). CBR and DCP Correlation for Class C Fly Ash-Stabilized Soil, Geotechnical Testing Journal, Vol. 29, No. 1, pp. 30-36.

[7] Edil, T.B. and Acosta, H.A. Stabilizing Soft Fine-Grained Soils with Fly Ash. Journal Material in Civil Engineering, Vol. 18, No. 2, 2006, pp. 283294.

[8] Dutta, R.K. and Sarda, V.K. CBR Behaviour of waste plastic strip-reinforced stone dust/fly ash overlying saturated clay. Turkish Journal of Engineering and Environmental Science, Vol. 31, 2007, pp. 171-182.

[9] Hughes, P., Glendinning, S. "Deep dry mix ground improvement of a soft peaty clay using blast furnace slag and red gypsum". Quarterly Journal of Engineering Geology and Hydrogeology, Vol. 37, No. 3, 2004, pp. 205-216.

[10] Indraratna, B., Utilization of lime, slag and fly ash for improvement of a colluvial soil in New South Wales, Australia, Geotechnical and Geological Engineering, Vol. 14, 1996, pp. 169-191.

[11] Kolay P.K, and Romali N.S.B. Stabilization of organic soil by different types of stabilizer. International Conference on Civil Engineering in the New Millennium: Opportunities and Challenges, Bengal Engineering and Science University, Shibpur, India, Vol. III, 2007, pp. 1394-1400.

[12] Singh, S.P., Tripathi, D.P. and Ranjith, P.G. Performance of evaluation of cement stabilized fly ash-GBFS mixes as a highway construction material. Waste Management, Vol. 28, 2008, pp. 1331-1337.

[13] Trzebiatowski BD, Edil TB, Benson CH Case study of subgrade stabilization using fly ash. State Highway 32, Port Washington, Wisconsin, 2000, pp. $123-136$.

[14] Gofar, N. Fundamental studies on compressibility of peat soil using large strain. Fundamental research report, 2005, Universiti Teknologi Malaysia.

[15] Huat, B.B.K. Organic and Peat Soils Engineering. Malaysian Book Publishers Association, 2004, UPM Press

[16] Noto, S. Peat Engineering Handbook. Civil engineering Research Institute, 1991

[17] Mesri, G., Stark, T. D., Ajlouni, M. A. \& Chen, C. S. "Secondary compression of peat with or without surcharging." Journal of Geotechnical and Geo-environmental Engineering. Vol. 123, No. 5, 1997, pp. 411-421.

[18] Hobbs, N. B. "Mire morphology and the properties and behavior of some British and foreign peats." Engineering. Geology, Vol. 19, No. 1, 1986, pp. 7-80.

[19] Macfarlane, I. C. Engineering Characteristics of Peat. In Muskeg Engineering Handbook. Proc., Ottawa, Canada, 1969, pp. 3-30. 